SHORT REPORT

\title{
Parents measuring pulses; an observational study
}

\section{J White, S Shepperd, P Yudkin, A Harnden, D Mant}

Parent reported pulse rates could provide important information on a child's clinical condition. The agreement between the parent's measurement of their child's pulse and a pulse oximeter was assessed following a brief educational intervention. Parents can be taught to measure the pulse of school age children, but have difficulty with preschool children.

A $\mathrm{n}$ accurate measurement of a child's pulse rate by the parent may provide helpful information for the GP managing a sick child. Previous studies of parents' measurement of children's pulse have either compared different techniques for palpating a pulse or have been carried out in a hospital setting on infants who have been asleep. ${ }^{12}$ Following a brief educational intervention we observed the agreement between parent measurement of their child's pulse and a pulse oximeter in a community setting.

\section{METHODS}

Parents and their children were referred by four general practices in Oxfordshire and by parents who had previously participated in this study of pulse measurement. The children were either healthy or had a minor illness. We sought informed consent from parents and asked them to provide details about their previous experience of taking a pulse. A research nurse showed parents how to locate their child's pulse: for those under 2 years the brachial pulse, and for those over 2 years the radial pulse. A Nellcor MP304 pulse oximeter was applied to the child, and parents were then asked to start counting the pulse and to call out the number of pulse beats they had counted after 30 seconds. The pulse oximeter was calibrated by Oxford Bio Signals and programmed to provide a reading of the child's pulse rate over the same 30 second period. The parent was blind to the pulse oximeter; however, the nurse observed the arterial waveform and discontinued a session if the waveform became irregular due to the child moving. We followed up parents at 1-7 days to reassess their measurement of a pulse compared with the pulse oximeter.

We plotted the difference between each parent's measurement of their child's pulse and the pulse oximeter reading against the average of these two measures using the method of Bland and Altman; ${ }^{4}$ 95\% limits of agreement were calculated (the range in which $95 \%$ of differences are expected to lie). We used multiple linear regression to examine the association between the number of days practised, the age of the child (years to one decimal place), and the difference between parent measure of pulse and pulse oximeter.

We obtained ethical approval for the study from the Central Oxford Research Ethics Committee.

\section{RESULTS}

One hundred and fourteen parents (110 (96\%) were mothers) and their children participated in the study. The children were aged between 6 months and 12 years (mean 4.9 years, SD 3.1). Sixteen parents (14\%) had left school at 16 years of age without further education; 30\% (34/114) had
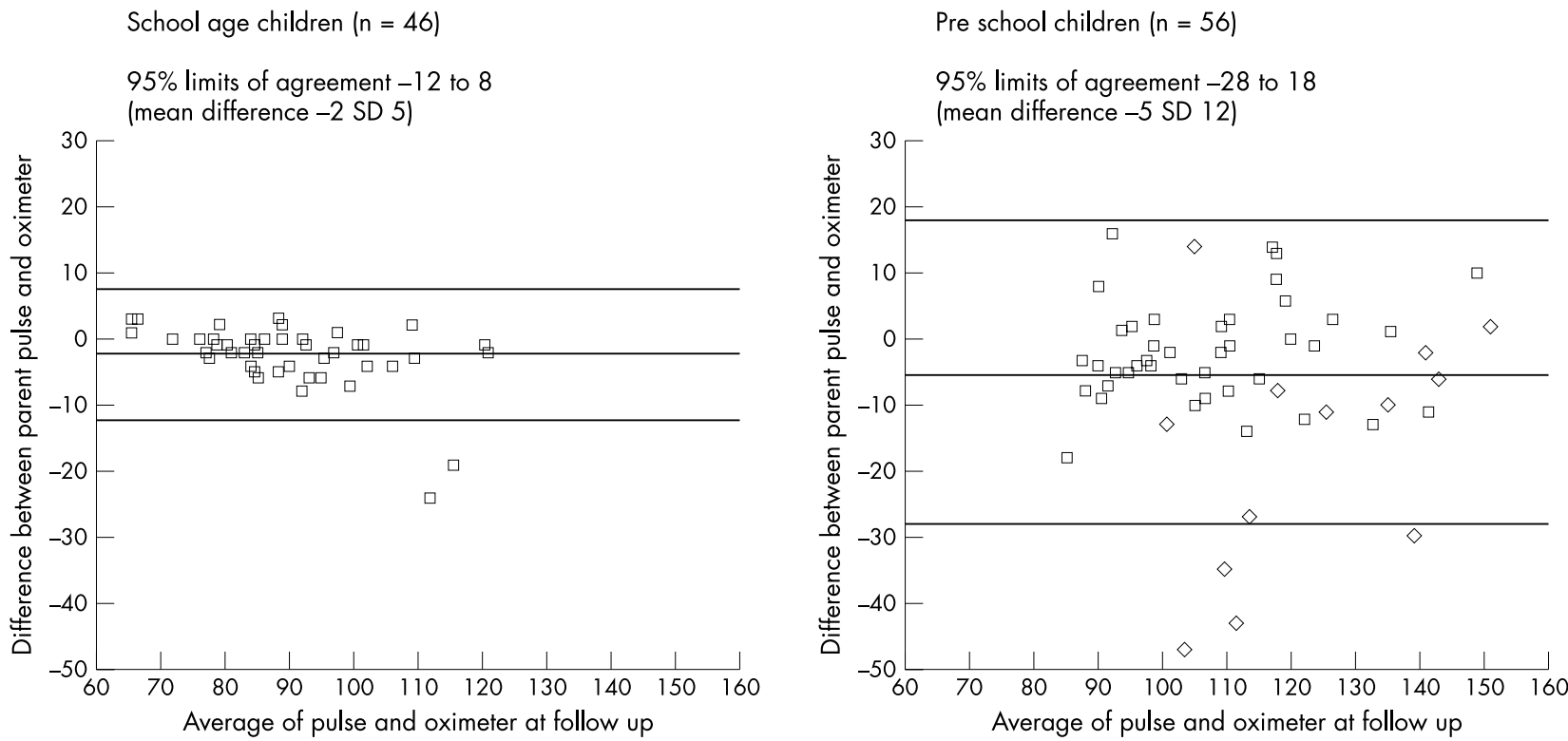

Figure 1 Agreement between parent measurement of pulse and pulse oximeter at follow up for preschool and school age children (Bland-Altman plot). Upper and lower lines are $95 \%$ limits of agreement. Diamonds indicate a child is restless when the pulse is being measured, and rectangles a still child. 
attended university. Two thirds of parents $(68 \%, 78 / 114)$ said they had taken a pulse before, though only $38 \%(30 / 78)$ of these had taken a pulse in the past year.

At one week follow up 8/114 parents declined a visit and 4/106 parents could not take their child's pulse because the child would not sit still. For the remaining 102 parents the mean (SD) difference between parental measurement and pulse oximeter reading was -4 (10) (parent measurement 99 (18) $v$ pulse oximeter $103(20)$ ), with 95\% limits of agreement of -24 to 16 . We detected no association between the number of days practised and the difference between parent's measurement of pulse and pulse oximeter $(p=0.38)$ but there was a negative association between this difference and the child's age $(p=0.02)$. Figure 1 shows the poorer agreement between parental pulse measurement and the pulse oximeter reading for preschool children $\left(\geqslant 4 \frac{1}{2}\right.$ years $)$ compared with school age children $\left(<4 \frac{1}{2}\right.$ years $)$.

\section{DISCUSSION}

In primary care it is often necessary to monitor children over a period of time as an illness develops, and this may involve parents in recording symptoms and simple clinical signs. Monitoring pulse rate is particularly useful as a rising pulse rate may provide an early indication of a serious childhood infection, and provide an assessment of change over time. This may help assess clinical severity.

Our observations show that parents of school age children can be taught to measure their child's pulse in a primary care setting. Measuring the pulse rate of younger children is more difficult and this difficulty increases as the child becomes restless. Similar observations have been reported for health professionals measuring the apical pulse in young children from birth to 24 months. ${ }^{3}$ Even though the educational background of the parents recruited was higher than the national average (only 14\% of parents left school at the minimum age), and our study was set in Oxfordshire (one of the least deprived areas of the UK) we found that parents of preschool children had difficulty measuring their child's pulse. We conclude it is unrealistic to expect parents to accurately record a pulse rate in preschool children.

\section{ACKNOWLEDGEMENTS}

Oxford Biosignals Ltd for supplying the pulse oximeter for the duration of the study.

\section{Authors' affiliations}

J White, S Shepperd, P Yudkin, A Harnden, D Mant, Department of Primary Care, University of Oxford, Institute of Health Sciences, Old Road, Oxford OX3 7LF, UK

This project is part of an MRC funded programme of research in childhood infection presenting in primary care

Correspondence to: Dr S Shepperd, Department of Primary Care, University of Oxford, Institute of Health Sciences, Old Road, Oxford OX3 7LF, UK

Accepted 21 June 2003

\section{REFERENCES}

1 Cavallaro DL, Melker RJ. Comparison of two techniques for detecting cardiac activity in infants. Crit Care Med 1983;11:189-90.

2 Tanner M, Nagy S, Peat JK. Detection of infant's heart beat/pulse by caregivers: a comparison of 4 methods. J Pediatr 2000;137:429-30.

3 Margolius FR, Sneed NV, Hollerbach AD. Accuracy of apical pulse rate measurements in young children. Nursing Research 1991;40:378-80.

4 Bland JM, Altman DG. Comparing methods of measurement: why plotting difference against standard method is misleading. Lancet 1995;346:1085-7.

5 Impicciatore P, Pandolfini C, Casella N, et al. Reliability of health information for the public on the world wide web: systematic survey of advice on managing fever in children at home. BMJ 1997;314:1875-9.

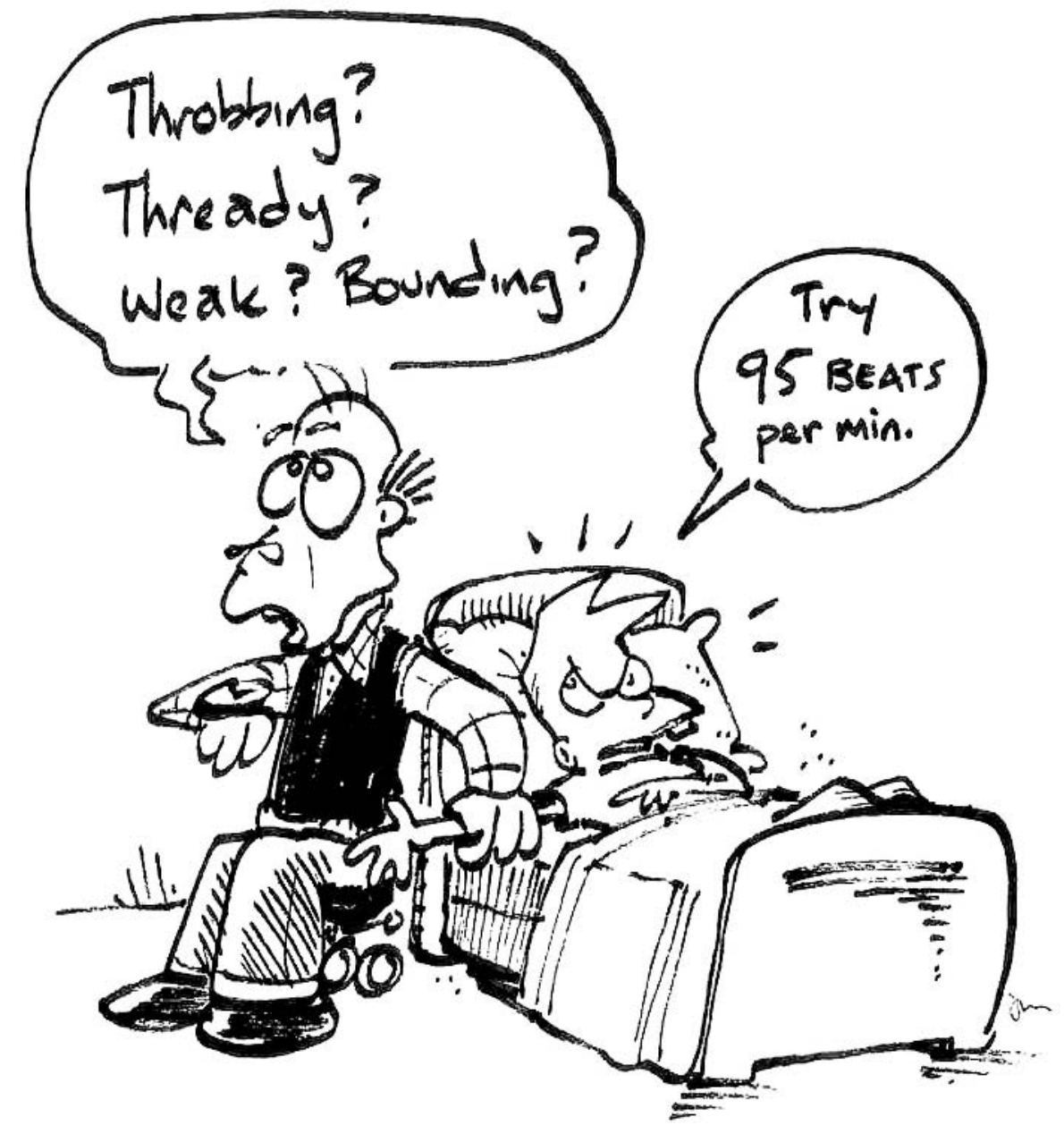

